\title{
Synthesis and Purification of Highly Hydrophobic Peptides Derived from the C-Terminus of Amyloid $\beta$-Protein
}

\author{
M.M. Condron ${ }^{1}$, B.H. Monien ${ }^{1}$ and G. Bitan ${ }^{2,3, *}$ \\ ${ }^{1}$ Department of Neurology, David Geffen School of Medicine, ${ }^{2}$ Brain Research Institute and ${ }^{3}$ Molecular Biology Insti- \\ tute, University of California at Los Angeles, USA
}

\begin{abstract}
Some biotechnological inventions involve expensive, sophisticated machines. Others are relatively simple innovations that nevertheless address, and solve difficult problems. Synthesis and purification of highly hydrophobic peptides can be a difficult and challenging task, particularly when these peptides have low solubility in both aqueous and organic solvents. Here we describe the synthesis and purification of a series of peptides derived from the hydrophobic Cterminus of the 42-residue form of amyloid $\beta$-protein (A $\beta 42)$, a peptide believed to be the primary cause for Alzheimer's disease (AD). The series of $C$-terminal fragments (CTFs) had the general formula $A \beta(x-42), x=28-39$, which potentially can be used as inhibitors of A $\beta 42$ assembly and neurotoxicity. Synthesis and purification of peptides containing 8-residues or less were straightforward. However, HPLC purification of longer peptides was problematic and provided $<1 \%$ yield in particularly difficult cases due to very poor solubility in the solvent systems used both in reverse- and in normal phase chromatography. Modification of the purification protocol using water precipitation followed by removal of scavengers by washing with diethyl ether circumvented the need for HPLC purification and provided these peptides with purity as high as HPLC-purified peptides and substantially increased yield.
\end{abstract}

\section{INTRODUCTION}

Amyloid $\beta$-protein $(\mathrm{A} \beta)$ is a small protein of unknown function whose accumulation and self-assembly are believed to be the seminal events causing Alzheimer's disease (AD) $[1,2]$. $A \beta$ is produced from the amyloid $\beta$-protein precursor (APP), a type 1 transmembrane protein, in two predominant forms comprising 40 or 42 amino acids, and termed $A \beta 40$ and $\mathrm{A} \beta 42$, respectively. Aging-related imbalance between production and clearance of $A \beta$ leads to elevation in its concentration, which in turn causes self-assembly of $A \beta$ into neurotoxic oligomers. The oligomers injure susceptible neurons by mechanisms that are not fully understood, aggregate further into larger assemblies, and eventually form polymers that deposit in the brain in the form of amyloid plaques, one of the pathological hallmarks of $\mathrm{AD}$. Thus, inhibition of $\mathrm{A} \beta$ assembly is a promising strategy for prevention of, and therapy for $\mathrm{AD}$.

Multiple lines of evidence point at $\mathrm{A} \beta 42$ as the form of $\mathrm{A} \beta$ that predominantly causes $\mathrm{AD}$. $\mathrm{A} \beta 40$ and $\mathrm{A} \beta 42$ exist in the plasma and cerebrospinal fluid (CSF) at a concentration ratio of $\sim 10: 1$, respectively, yet $\mathrm{A} \beta 42$ is deposited first during the development of $\mathrm{AD}$ [3], is the predominant component in parenchymal plaques [4], and is more neurotoxic than $A \beta 40$ [5]. An increase in the $A \beta 42 / A \beta 40$ concentration ratio is associated with early onset familial AD [6], whereas treatments that decrease this ratio reduce the risk for AD [7].

$\mathrm{A} \beta 40$ and $\mathrm{A} \beta 42$ form distinct oligomer populations in vitro [8]. Several kinds of oligomers formed only by $A \beta 42$ have been shown to be highly neurotoxic [9-11]. Direct

\footnotetext{
*Address correspondence to this author at the Department of Neurology, David Geffen School of Medicine, University of California at Los Angeles, USA; E-mail: gbitan@mednet.ucla.edu
}

comparison of $\mathrm{A} \beta 40$ and $\mathrm{A} \beta 42$ oligomers formed under similar conditions demonstrate substantially higher toxicity of the $A \beta 42$ oligomers $[12,13]$. Because the only structural difference between $A \beta 40$ and $A \beta 42$ is the absence or presence of the last two amino acids, $\mathrm{Ile}^{41}-\mathrm{Ala}^{42}$, respectively, it is reasonable to hypothesize that the $\mathrm{C}$-terminus plays an important role in the assembly and/or toxicity of $A \beta 42$. In support of this hypothesis, increased toxicity of $A \beta 42$ relative to $A \beta 40$ correlates not only with distinct oligomer populations, but also with increased conformational stability [1417] and a putative quasi-stable turn conformation [18-20] in the C-terminal region of $\mathrm{A} \beta 42$ but not $\mathrm{A} \beta 40$.

The C-terminal region (last 14 residues) of $\mathrm{A} \beta 42$ is highly hydrophobic and believed to reside within the membrane before $A \beta$ is cleaved from APP. Thus, we hypothesized that intermolecular association of the C-termini of several A $\beta 42$ monomers, leading to formation of a core in which hydrophobic residues are sequestered from the aqueous environment, may be a major driving force for formation of $\mathrm{A} \beta$ oligomers. If that is the case, we reasoned that $\mathrm{C}$ terminal fragments (CTFs) of $\mathrm{A} \beta 42$ might compete with the $\mathrm{C}$-terminus of full-length $\mathrm{A} \beta 42$ and disrupt oligomer formation (Fig. 1). To test this hypothesis, we set up to synthesize a series of $A \beta 42$-derived CTFs [A $\beta(x-42), x=28-39]$ and test their ability to inhibit A $\beta 42$ self-assembly and toxicity. Here we report on the synthetic challenges associated with obtaining long CTFs and ways to overcome these challenges. Results of biological and structural characterization of the CTFs will be reported elsewhere.

Synthesis and purification of peptides comprising mainly hydrophobic residues is challenging because of the low solubility of these peptides in both hydrophilic and hydrophobic solvents and their high tendency to aggregate [21-23]. A $\beta$ 
and its derivatives are known to be difficult to synthesize and obtain in high purity $[24,25]$. In fact, an early solid-state NMR investigation of $A \beta(34-42)$ has reported that this peptide readily aggregated into amyloid fibrils [26]. Nevertheless, the potential of A $\beta 42$-derived CTFs as inhibitors of A $\beta 42$ toxicity made them attractive for us to synthesize and characterize.

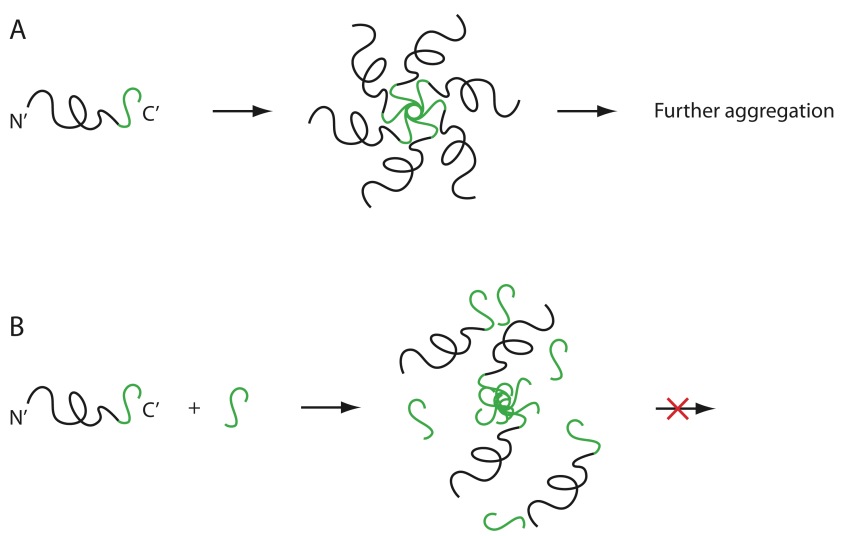

Fig. (1). Schematic representation of putative mechanism of action of A 342 -derived CTF. A) The $\mathrm{C}$-termini of several A $\beta 42$ molecules are hypothesized to form the hydrophobic core of the oligomer. B) CTFs derived from the C-terminus of $\mathrm{A} \beta 42$ may displace the $\mathrm{C}$ terminus of the full-length peptide, leading to disruption of oligomerization.

\section{METHODS AND MATERIALS}

\section{Reagents and Equipment}

Protected amino acids were purchased from Novabiochem (San Diego, CA). N-methylpyrrolidone (NMP), dichloromethane (DCM), acetonitrile (ACN), acetic acid, and trifluoroacetic acid (TFA) were from Fisher Scientific (Pittsburgh, PA). Piperidine, 1-hydroxybenzotriazole, and O-benzotriazole-N,N,N',N'-tetramethyluronium hexafluorophosphate (HBTU) were from Anaspec (San Jose, CA) or Applied Biosystems (Foster City, CA). N,N-diisopropylethyamine (DIPEA) was from Applied Biosystems. Diethyl ether, ethanedithiol (EDT), thioanisole, and triisopropylsilane (TIPS) were from Sigma/Aldrich (St. Louis, MO). All the chemicals used were of analytical grade or higher. Deionized water was produced using a Milli-Q A10 system (Millipore, Billerica, MA). Solid-phase peptide synthesis resins were all substituted with Fmoc-Ala and included Wang resin (200-400 mesh, $0.7 \mathrm{mmol} / \mathrm{g}$ from Bachem, Torrance, CA or 100-200 mesh, $0.41 \mathrm{mmol} / \mathrm{g}$ from Novabiochem, San Diego, CA), TGA resin (100-200 mesh, 0.21 or $0.23 \mathrm{mmol} / \mathrm{g}$, Novabiochem), or 2-chlorotrityl resin (100-200 mesh, $0.6 \mathrm{mmol} / \mathrm{g}$, Novabiochem). Analytical HPLC analysis was done using a 510 system (Waters, Milford, MA) with $250 \times 5 \mathrm{~mm}$ diphenyl or C4 columns (Vydac, Hesperia, CA). HPLC coupled with mass spectrometry (MS) analysis was done using a LCQ Deca mass spectrometer with electrospray ionization probe coupled to a Surveyor HPLC system (ThermoScientific, Waltham, MA) with $150 \times 1 \mathrm{~mm}$ diphenyl or C4 columns (Vydac). The mass spectrometer was tuned and optimized on a regular basis at least once a month and calibrated periodically using molecular weight standards according to the manufacturer's instructions. Semi-preparative HPLC purification was performed using a Dynamax system (Rainin, Oakland, CA) with $250 \times 20 \mathrm{~mm} \mathrm{C4}$ or diphenyl columns
(Vydac). Amino acid analysis (AAA) was performed using an Empower AccQTag system (Waters).

\section{Peptide Synthesis}

All the peptides were synthesized by 9-fluorenylmethoxycarbonyl (FMOC) chemistry using automated Applied Biosystems 433A synthesizers. The synthesis scale was between 0.20-0.25 mmol. The coupling and deprotection cycles were extended from the manufacturer recommended times, 30 and $10 \mathrm{~min}$, respectively, to 60 and $30 \mathrm{~min}$, respectively. Coupling cycles were performed using 4 eq. of incoming amino acid, HBTU, and DIPEA in NMP. FMOC deprotection was done using $20 \%$ piperidine in NMP. The $\varepsilon-\mathrm{NH}_{2}$ group of Lys was protected by tert-butoxycarbonyl (BOC). Cleavage of the peptide from the resin and side-chain deprotection (where appropriate) was performed using $10 \mathrm{~mL}$ of the following mixtures: A) 9.5:0.5 - TFA: $\mathrm{H}_{2} \mathrm{O}$; B) 9.25:0.5:0.25 TFA: $\mathrm{H}_{2} \mathrm{O}: E D T$; $)$ 8.75:0.5:0.5:0.25 - TFA: $\mathrm{H}_{2} \mathrm{O}$ :thioanisole: EDT; or D) 9.5:0.25:0.25 - TFA:EDT:TIPS. After filtration of the resin, several methods were used for isolation of the crude peptide from the cleavage mixture (see Results). The integrity of the final products was verified by MS and AAA (Table 1).

\section{RESULTS}

With exception of the longest CTF we prepared, $\mathrm{A} \beta(28$ 42) (Lys-Gly-Ala ${ }^{30}$-Ile-Ile-Gly-Leu-Met-Val-Gly-Gly-Val$\mathrm{Val}^{40}{ }^{4}$-Ile-Ala, full-length $\mathrm{A} \beta$ numbering is used throughout the manuscript), all other CTFs comprised only amino acids with non-charged side-chains. The Gly residues in positions $29,33,37$, and 38 were the only hydrophilic residues in the sequence, whereas all other residues were hydrophobic. Previous work suggested that $A \beta(34-42)$ readily formed $\beta$-sheetrich fibrillar aggregates [26]. Therefore, we anticipated that the synthesis and purification of the CTFs would become difficult above a certain length. Encouragingly, using the protocol we routinely use for the synthesis of full-length A $\beta 42$, which includes extended coupling and deprotection times (see Methods and Materials) we could synthesize all peptide sequences and did not encounter special problems in any coupling/deprotection cycle as determined by the synthesizer's online UV monitoring of deprotection products.

The type of resin used was an important determinant of synthesis success. Initially, peptides were synthesized using a 200-400 mesh, 0.4-0.6 mmol/g Wang resin from Novabiochem. This resin worked well in all the cases it was used, but unfortunately, during the period of the project the company discontinued this particular resin. We therefore switched to a 100-200 mesh Wang resin from Novabiochem and found out that with this resin, substitution level had to be kept under $0.5 \mathrm{mmol} / \mathrm{g}$ for the synthesis to be successful. A $\beta(39-42)$ through $A \beta(33-42)$ were synthesized successfully with this resin but longer CTFs produced negligible yields. Therefore, $\mathrm{A} \beta(32-42)$ and longer peptides were synthesized using a 100-200 mesh TGA resin (Novabiochem), for which we also had to use low substitution levels. Towards the end of the project period, we also have used successfully a 200-400 mesh, $0.7 \mathrm{mmol} / \mathrm{g}$ Wang resin from Bachem.

Isolation of the CTFs from the crude cleavage mixture was relatively straightforward for $A \beta(39-42)$ through $A \beta(35$ 42) but became difficult for $A \beta(34-42)$ and longer peptides. 
In initial experiments, CTFs were cleaved from the resin in $10 \mathrm{~mL}$ cleavage mixture B for $120 \mathrm{~min}$. The resin was filtered out and the filtrate volume reduced to $1-2 \mathrm{~mL}$ gently under low vacuum. The crude peptide was then precipitated by dilution with $50 \mathrm{~mL}$ of ice-cold diethyl ether and collected by filtration. The crude peptide was re-dissolved in milli-Q water and purified by semi-preparative HPLC with a gradient of $20-100 \%$ solvent $\mathrm{B}$ over 40 min (solvent $\mathrm{A}=2 \%$ ACN, $0.1 \%$ AcOH, $0.02 \%$ TFA in milli-Q water, solvent B $=98 \% \mathrm{ACN}, 0.1 \% \mathrm{AcOH}, 0.02 \%$ TFA in milli-Q water). All HPLC separations were performed at room temperature with UV monitoring at $214 \mathrm{~nm}$. Flow rates were $5 \mathrm{~mL} / \mathrm{min}$ for semi-preparative HPLC, $1 \mathrm{~mL} / \mathrm{min}$ for analytical HPLC, and $0.1 \mathrm{~mL} / \mathrm{min}$ for LC-MS. Initially, both diphenyl and $\mathrm{C} 4$ columns (both analytical and semi-preparative) were used. C4 columns were found to have somewhat better resolution relative to the diphenyl columns and were used in subsequent experiments. This protocol yielded $A \beta(39-42)$ through $A \beta(35-42)$, and $A \beta(28-42)$ in high purity and moderate yield (Table 1).

When attempting to use the same purification protocol for $A \beta(34-42)$ through $A \beta(29-42)$, we realized that these peptides did not precipitate by dilution of the concentrated cleavage mixture in ice-cold ether. Therefore, we tried to purify the crude peptides by loading the cleavage mixture directly onto an HPLC column. To simplify the cleavage mixture, we attempted excluding all the scavengers except water, taking into account that none of the amino acids used for the synthesis contained a side-chain protecting group and that the only moiety predicted to be sensitive to carbocations was the thioether in the side-chain of $\mathrm{Met}^{35}$. Ten $\mathrm{mL}$ cleavage mixture $A$ were used to cleave each peptide from the resin for $120 \mathrm{~min}$. After filtration of the resin, the volume was reduced to $1-2 \mathrm{~mL}$ and loaded directly onto an HPLC column. Because the mixture contained high concentration of TFA, which could partially dissolve the resin in silicabased columns, we used in these experiments a polymerbased, $250 \times 21 \mathrm{~mm}$ polyhydroxyethyl A column (The Nest Group, Southborough, MA). However, we could not recover meaningful quantities of peptide from the column using this protocol.

In subsequent experiments, we therefore attempted to go back to the silica-based $\mathrm{C} 4$ column used for purification of shorter CTFs. In order to avoid harming the silica-based resin, after reducing the volume of the cleavage mixture to 1 $2 \mathrm{~mL}$, it was diluted in a mixture containing milli-Q water, $\mathrm{ACN}$, and in some cases 2,2,2-trifluoroethanol (TFE) or 1,1,1,3,3,3-hexafluoroisopropanol (HFIP). These fluorinated alcohols are known to induce $\alpha$-helical conformation and help disaggregate $\beta$-sheet-rich amyloid protein aggregates. This step was adjusted empirically for each peptide and each synthesis batch with the goal to keep most of the crude peptide in solution. It was impossible to measure precisely the relative quantity of each solvent in each experiment. The final volume loaded onto the $\mathrm{C} 4$ column was $\sim 10 \mathrm{~mL}$. Using this procedure, small amount of product could be purified (see Table 1). However, all the peptides contained a sideproduct that eluted with highly similar retention time to the

Table 1.

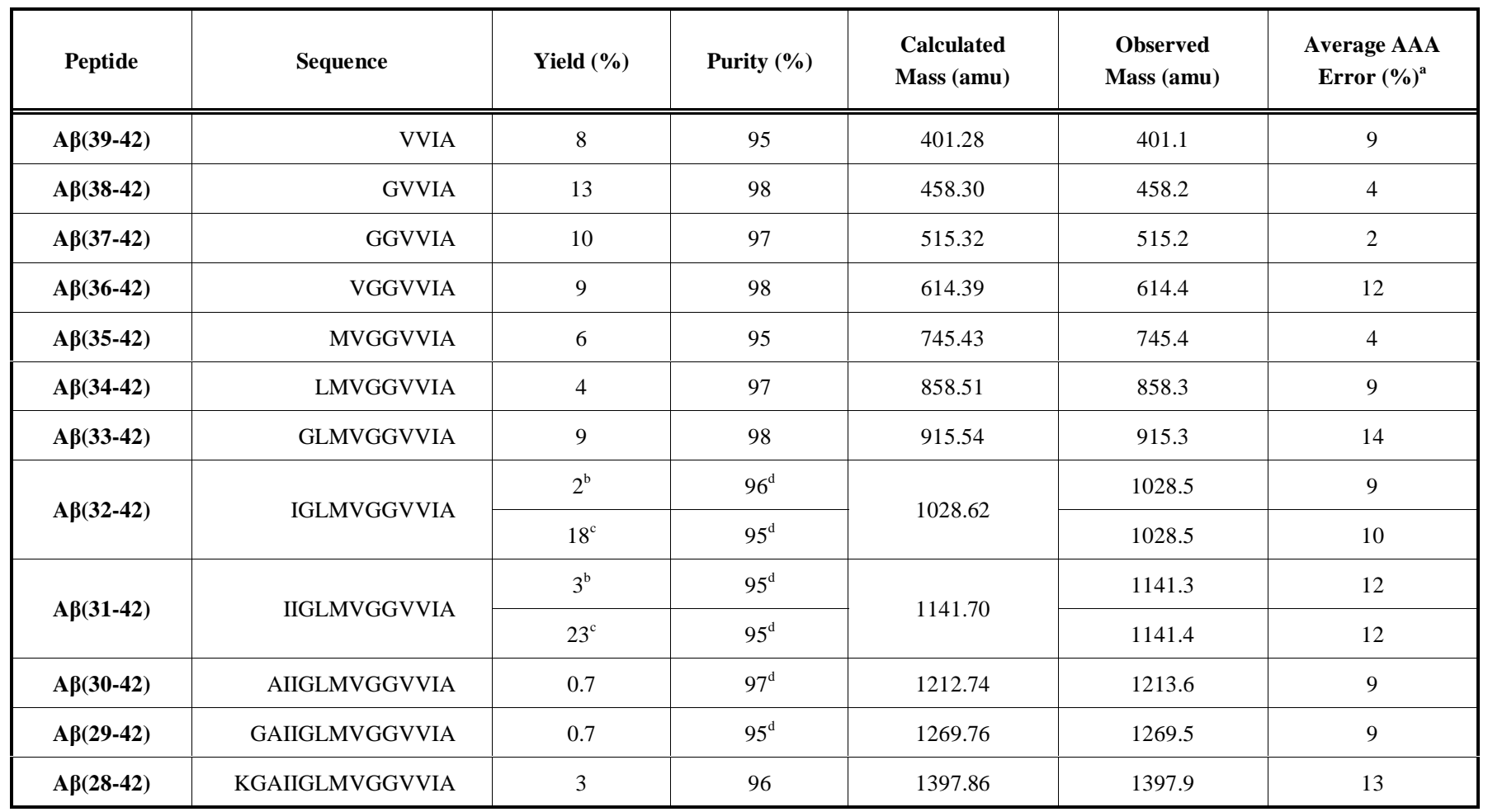

a) Average $\%$ error for each amino acid type divided by number of amino acids.

b) Purified by semi-preparative HPLC.

c) Precipitated in water and washed with diethyl ether.

d) For these peptides the purity could not be determined using UV monitoring of HPLC. Therefore, the assessment is based on a chromatogram for which the total ion current was measured continuously by a mass-spectrometer. 
desired product and displayed a molecular mass increase of 164 mass units. We interpreted this result to signify that during the cleavage reaction, some of the 4-hydroxymethylphenoxyacetamide linker connecting the peptide to the TGA resin, got cleaved and formed this adduct, presumably by reaction with the thioether side-chain of Met. The close proximity in retention time of the adduct and the pure peptide compromised the yield substantially, in some cases to $<1 \%$. In addition, the absorbance peak of the adduct was considerably larger than that of the pure peptide (Fig. 2), either because of higher extinction coefficient at $214 \mathrm{~nm}$ or due to higher solubility of the side product containing the adduct relative to the desired peptide that did not contain the adduct. To reduce this side product, we attempted using cleavage mixtures 3 or 4 . However, although the scavengers reduced the amount of the side product, its apparent relative abundance in HPLC analysis did not change significantly because of the difficulty to detect the desired product. We also attempted to use 2-chlorotrityl resin instead of TGA resin, to eliminate the presence of the 4-hydroxymethylphenoxyacetamide linker altogether. However, these experiments yielded negligible amounts of desired products.

The low solubility of the CTFs, $A \beta(34-42)$ through $A \beta$ (29-42), in the HPLC solvent system and the need to separate them from closely migrating impurities caused very low recovery of the peptides from the HPLC columns used. Although some of the material loaded onto the column was eluted, during the course of the work we realized that the bulk of these peptides could not be recovered, likely because they precipitated out of solution during the early steps of the elution and did not re-dissolve in later stages or during wash steps. The recovery decreased with increasing peptide length. Peptides longer than $A \beta(33-42)$ necessitated analyzing fractions collected during semi-preparative HPLC purification by MS because the amount of peptide soluble in the mobile phase was too low to detect by UV absorbance (Fig. 2).

To overcome these difficulties, eventually, we modified the purification protocol and found out that CTFs that did not precipitate by addition of diethyl ether to the crude cleavage mixture could be isolated by water precipitation. This procedure was applied only to $A \beta(31-42)$ and $A \beta(32-42)$ but likely is applicable to $A \beta(34-42)$ through $A \beta(29-42)$. The best results were obtained by using cleavage mixture 4 for $120 \mathrm{~min}$. Following this step, $A \beta(31-42)$ or $A \beta(32-42)$ were precipitated by dilution with $25 \mathrm{~mL}$ of ice-cold milli-Q water. The precipitate was filtered, reconstituted in $60 \% \mathrm{ACN}$ and lyophilized. The lyophilizate was washed with diethyl ether to remove scavengers and re-precipitated by centrifugation. The ether was discarded and the peptide dried in an RT100 SpeedVac concentrator (Savant, Ramsey, MN). The dry peptide was reconstituted in $60 \% \mathrm{ACN}$ and lyophilized. This protocol yielded $A \beta(31-42)$ and $A \beta(32-42)$ at $23 \%$ and $18 \%$ yield, respectively. Because HPLC analysis could not be used for reliable estimation of peptide purity, the purity was assessed by HPLC-MS and AAA (Table 1).

Fig. (3) shows an example of HPLC-MS analysis of $\mathrm{A} \beta(31-42)$. The peptide appears as a small broad peak in the

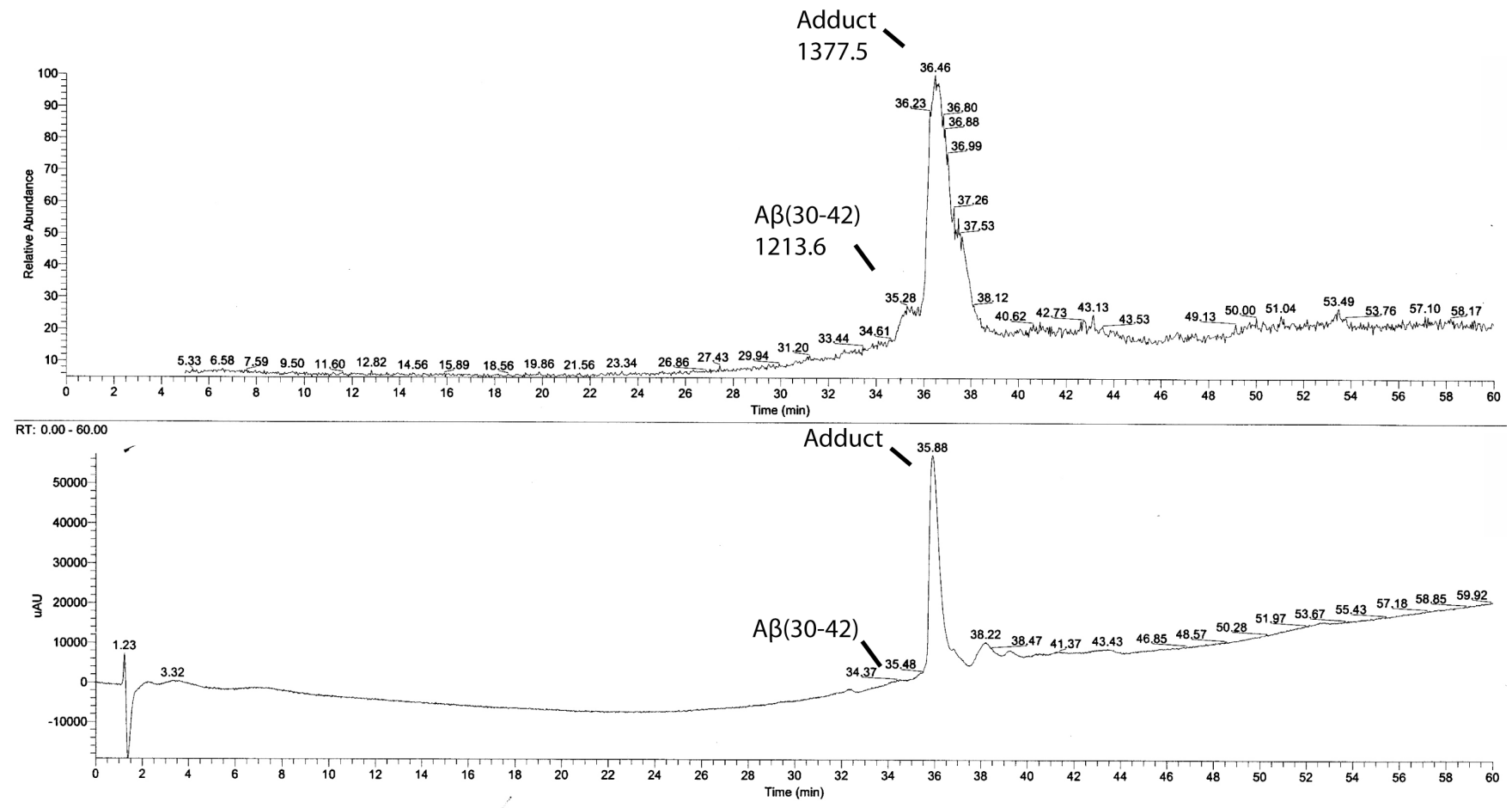

Fig. (2). HPLC analysis of partially purified $A \beta(30-42)$. Collected fractions from semi-preparative purification of $A \beta(30-42)$ were pooled together, concentrated, and an aliquot injected onto a microbore C4 column interfaced with UV and MS detectors in tandem. Elution was done using a gradient of $20-80 \%$ solvent B during $60 \mathrm{~min}$ at a flow rate of $100 \mu \mathrm{L} / \mathrm{min}$. At this flow rate, the delay between the UV and MS detectors is $0.6 \mathrm{~min}$. The upper panel shows the TIC trace, in which a broad peak at $35.28 \mathrm{~min}$ is the desired product, followed by the +164 amu adduct at $36.46 \mathrm{~min}$. The lower panel shows the UV trace (at $214 \mathrm{~nm}$ ), in which the adduct is a large peak at 35.88 min preceded by a small shoulder, which is the desired product. 


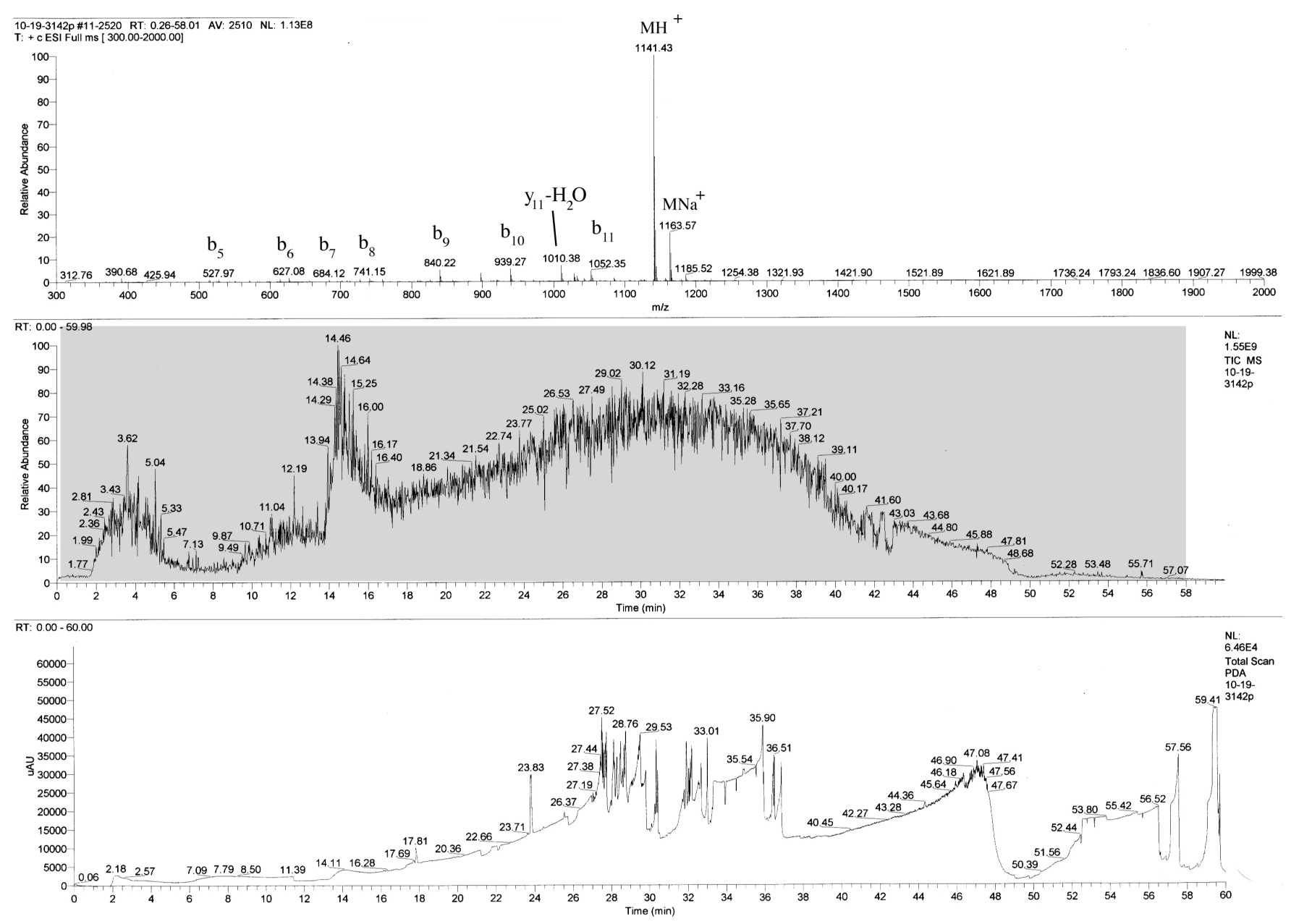

Fig. (3). HPLC-MS analysis of water-precipitated $A \beta(31-42)$. A $\beta(31-42)$ was purified by water precipitation and washing with diethyl ether. An aliquot was dissolved in $60 \% \mathrm{ACN}$ and fractionated on a microbore $\mathrm{C} 4$ column as described in the legend of Fig. (2). The lower panel shows the UV trace at $214 \mathrm{~nm}$. A small and wide peak at $14.11 \mathrm{~min}$ is a fast migrating fraction of A $\beta(31-42)$. The middle panel shows the TIC trace. The upper panel shows the combined spectra of all the time points between 0.26 and 58.01 min (gray box in middle panel). A main peak of $A \beta(31-42)$ and minor peaks of its gas phase-induced fragments are the only masses observed.

UV trace followed by multiple narrow peaks that probably represent negligible impurities and/or system "noise." The total ion current (TIC) trace of the MS detector shows a $\sim 3$ min broad peak followed by a $\sim 30$ min broad peak, both likely corresponding to the desired product. The combined mass-spectrum of the entire chromatogram (Fig. 3, gray box) shows $A \beta(31-42)$ as the only product. In addition, the average AAA error (Table 1) is similar to that of the CTFs purified by HPLC, suggesting similar degree of purity.

\section{DISCUSSION}

Despite decades of research, AD is a disease that currently cannot be cured or prevented. Currently approved drugs for $\mathrm{AD}$ treat the symptoms, rather than the causes of the disease and provide only moderate and temporary relief [27]. $\mathrm{AD}$ is the leading cause of dementia and one of the leading causes of death among elderly people [28]. A recent report by the Alzheimer Association indicated that in 2007, the prevalence of AD in the US has exceeded 5 million and may increase up to 16 million by the middle of the century if no cure is found [29]. As the population ages, this situation may lead to an epidemic. Current estimates of cost of care for patients with $\mathrm{AD}$ in the US are over $\$ 148$ billion a year [29]. Numbers in other countries also are highly alarming [30-32]. Thus, there is an urgent need for disease-modifying therapeutic strategies for AD. Following the modified Amyloid Cascade Hypothesis [2], leading strategies are focusing on $\mathrm{A} \beta$ as a primary cause of $\mathrm{AD}$ and therefore target inhibition of $A \beta$ production, enhancement of $A \beta$ clearance, or disruption of $A \beta$ assembly [33]. The normal physiologic function of $\mathrm{A} \beta$ is unknown, thus inhibiting its production or increasing its clearance may lead to adverse side effects. In contrast, $A \beta$ self-association into oligomers and polymers is purely a pathologic phenomenon and therefore is an attractive target for development of inhibitors.

Multiple examples of small molecule inhibitors of $A \beta$ fibrillization exist in the literature [34]. Recently, several groups reported inhibitors of $A \beta$ oligomer formation [35-38], following a paradigm shift in the amyloid field that identified pre-fibrillar oligomers as the primary cause of cytotoxicity $[39,40]$. Inhibitor selection in these studies was based on empirical findings, rather than on systematic rational design. 
Therefore, little can be deduced about their mechanism of action. In contrast, structure-based inhibitor design approaches can provide mechanistic data that can be used to improve inhibitor efficacy and pharmacokinetics.

The main driving force for $A \beta$ self-assembly likely is intermolecular hydrophobic interactions that lead to sequestering hydrophobic patches from the aqueous environment [18]. Thus, a reasonable rational design approach to inhibiting the assembly is to use short peptides derived from hydrophobic regions in $A \beta$ itself, which can compete with the same region in the full-length $A \beta$. Following this rationale, a large body of work has focused on peptides derived from the central hydrophobic cluster $(\mathrm{A} \beta(17-21))$ [41, 42], which had been shown to be important for $A \beta$ fibrillogenesis [43], though not necessarily for the formation of early oligomers. Because oligomers of A $\beta 42$ likely are the main culprit causing neurotoxicity in $\mathrm{AD}$, we decided to use peptides derived from the C-terminus of $\mathrm{A} \beta 42$ as potential inhibitors of oligomerization and toxicity of full-length $A \beta 42$. Although this seems like an attractive strategy, presumably it has not been attempted previously because of the difficulty in preparing and solubilizing these highly hydrophobic peptides, particularly of longer CTFs.

The systematic study reported here shows that the synthesis and purification of $\mathrm{A} \beta 42 \mathrm{CTFs}$ longer than 8-amino acids indeed are difficult. Although no particular problems were encountered during the synthesis itself, the low solubility of these CTFs in both aqueous and organic solvents made their purification by common RP-HPLC techniques difficult. Although the bulk of the crude preparation presumably contained the desired peptides, RP-HPLC analysis, particularly of the long CTFs, was substantially skewed, over-representing impurities with higher solubility and/or higher absorbance at the detection wavelength (Figs. 2 and 3). For the same reasons, recovery of the pure peptides following preparative or semi-preparative HPLC purification was very low. To solve this difficulty, we adopted a protocol that circumvented the need for HPLC purification by taking advantage of the same properties that make HPLC purification difficult - low solubility in both hydrophilic and hydrophobic solvents. By precipitating the peptides in water followed by resuspending and washing with diethyl ether, we obtained some of the most difficult sequences in the CTF series with high purity and moderate yield (Fig. 3 and Table $\mathbf{1}$ ).

The solubility of the purified CTFs in aqueous buffers ranged from a few micromolar to a few hundred micromolar [44]. Somewhat surprisingly, although $A \beta(28-42)$ could be purified by HPLC at acidic $\mathrm{pH}$ with reasonable yield, it was the least soluble CTF at $\mathrm{pH} 7.4$ [44]. The solubility of all other CTFs was sufficient for biological and biophysical studies, the details of which will be published elsewhere. These studies show that the CTFs are capable of inhibiting A 342 -induced neurotoxicity and therefore are good lead candidates for developing peptidomimetic inhibitors with improved pharmacokinetic characteristics, for prevention and treatment of $\mathrm{AD}$.

\section{ACKNOWLEDGMENTS}

This study was supported by grants AG027818 from the NIH/NIA and 2005/2E from the Larry L. Hillblom Foundation, and by a generous gift from the Turken family.

\section{REFERENCES}

[1] Hardy JA, Higgins GA. Alzheimer's disease: the amyloid cascade hypothesis. Science 1992; 256(5054): 184-85.

[2] Hardy J, Selkoe DJ. The amyloid hypothesis of Alzheimer's disease: progress and problems on the road to therapeutics. Science 2002; 297(5580): 353-56.

[3] Suzuki N, Cheung TT, Cai XD, et al. An increased percentage of long amyloid $\beta$ protein secreted by familial amyloid $\beta$ protein precursor (BAPP717) mutants. Science 1994; 264(5163): 1336-40.

[4] Suo ZM, Humphrey J, Kundtz A, et al. Soluble Alzheimers $\beta$ amyloid constricts the cerebral vasculature in vivo. Neurosci Lett 1998; 257(2): 77-80.

[5] Younkin SG. Evidence that Aß42 is the real culprit in Alzheimer's disease. Ann Neurol 1995; 37(3): 287-88.

[6] Scheuner D, Eckman C, Jensen M, et al. Secreted amyloid $\beta$ protein similar to that in the senile plaques of Alzheimer's disease is increased in vivo by the Presenilin 1 and 2 and APP mutations linked to familial Alzheimer's disease. Nat Med 1996; 2(8): 864-70.

[7] Weggen S, Eriksen JL, Das P, et al. A subset of NSAIDs lower amyloidogenic A $\beta 42$ independently of cyclooxygenase activity. Nature 2001; 414(6860): 212-16.

[8] Bitan G, Kirkitadze MD, Lomakin A, et al. Amyloid $\beta$-protein $(A \beta)$ assembly: $A \beta 40$ and $A \beta 42$ oligomerize through distinct pathways. Proc Natl Acad Sci USA 2003; 100(1): 330-35.

[9] Lambert MP, Barlow AK, Chromy BA, et al. Diffusible, nonfibrillar ligands derived from $A \beta 1-42$ are potent central nervous system neurotoxins. Proc Natl Acad Sci USA 1998; 95(11): 6448-53.

[10] Fradinger EA, Spring SM, Condron MM, et al. Structural stabilization of oligomers increases neurotoxicity of the amyloid $\beta$-protein (A $\beta$ ). Paper presented at the 34th Annual Meeting of the Society for Neuroscience, Washington, DC, 2005. Abstract number 587.14.

[11] Barghorn S, Nimmrich V, Striebinger A, et al. Globular amyloid $\beta$ peptide oligomer - a homogenous and stable neuropathological protein in Alzheimer's disease. J Neurochem 2005; 95(3): 834-47.

[12] Dahlgren KN, Manelli AM, Stine WB, et al. Oligomeric and fibrillar species of amyloid- $\beta$ peptides differentially affect neuronal viability. J Biol Chem 2002; 277(35): 32046-53.

[13] Hoshi M, Sato M, Matsumoto S, et al. Spherical aggregates of $\beta$ amyloid (amylospheroid) show high neurotoxicity and activate tau protein kinase I/glycogen synthase kinase-3 $\beta$. Proc Natl Acad Sci USA 2003; 100(11): 6370-75.

[14] Murakami K, Irie K, Ohigashi H, et al. Formation and stabilization model of the 42-mer $A \beta$ radical: implications for the long-lasting oxidative stress in Alzheimer's disease. J Am Chem Soc 2005; 127(43): 15168-74

[15] Riek R, Guntert P, Döbeli H, et al. NMR studies in aqueous solution fail to identify significant conformational differences between the monomeric forms of two Alzheimer peptides with widely different plaque-competence, $\mathrm{A} \beta(1-40)$ ox and $\mathrm{A} \beta(1-42) \mathrm{ox}$. Eur J Biochem 2001; 268(22): 5930-36

[16] Yan Y, Liu J, McCallum SA, et al. Methyl dynamics of the amyloid- $\beta$ peptides $A \beta 40$ and $A \beta 42$. Biochem Biophys Res Commun 2007; 362(2): 410-14.

[17] Lazo ND, Grant MA, Condron MC, et al. On the nucleation of amyloid $\beta$-protein monomer folding. Protein Sci 2005; 14(6): 158196.

[18] Urbanc B, Cruz L, Yun S, et al. In silico study of amyloid $\beta$-protein folding and oligomerization. Proc Natl Acad Sci USA 2004; 101(50): 17345-50.

[19] Yun S, Urbanc B, Cruz L, et al. Role of Electrostatic Interactions in Amyloid $\beta$-Protein $(\mathrm{A} \beta)$ Oligomer Formation: A Discrete Molecular Dynamics Study. Biophys J 2007; 92(11): 4064-77.

[20] Krafft GA, Joyce J, Jerecic J, et al. Design of arrested-assembly A 1 1-42 peptide variants to elucidate the ADDL oligomerization pathway and conformational specificity of anti-ADDL antibodies. Paper presented at the 35th Annual Meeting of the Society for Neuroscience, Atlanta, GA, 2006. Abstract number 509.5.

[21] Sampson WR, Patsiouras H, Ede NJ. The synthesis of 'difficult' peptides using 2-hydroxy-4-methoxybenzyl or pseudoproline amino acid building blocks: a comparative study. J Pept Sci 1999; 5(9): 403-09.

[22] Ajikumar PK, Devaky KS. Solid phase synthesis of hydrophobic difficult sequence peptides on BDDMA-PS support. J Pept Sci 2001; 7(12): 641-49.

[23] Nilsson MR, Nguyen LL, Raleigh DP. Synthesis and purification of amyloidogenic peptides. Anal Biochem 2001; 288(1): 76-82. 
[24] Tickler AK, Clippingdale AB, Wade JD. Amyloid- $\beta$ as a "difficult sequence" in solid phase peptide synthesis. Protein Pept Lett 2004; 11(4): 377-84.

[25] Sohma Y, Chiyomori Y, Kimura M, et al. 'O-Acyl isopeptide method' for the efficient preparation of amyloid $\beta$ peptide $1-42 \mathrm{mu}$ tants. Bioorg Med Chem 2005; 13(22): 6167-74.

[26] Lansbury PT, Costa PR, Griffiths JM, et al. Structural model for the $\beta$-amyloid fibril based on interstrand alignment of an antiparallel-sheet comprising a C-terminal peptide. Nat Struct Biol 1995; 2(11): 990-98.

[27] Monien BH, Apostolova LG, Bitan G. Early diagnostics and therapeutics for Alzheimer's disease-how early can we get there? Expert Rev Neurother 2006; 6(9): 1293-306.

[28] Ewbank DC. Deaths attributable to Alzheimer's disease in the United States. Am J Publ Health 1999; 89(1): 90-92.

[29] Every 72 seconds someone in America develops Alzheimer's. Alz.org [hompage on the Internet]. Washington, DC: The Alzheimer Association. Available from http://www.alz.org/news_and_ events_rates_rise.asp

[30] Leung GM, Yeung RY, Chi I, et al. The economics of Alzheimer disease. Dement Geriatr Cogn Disord 2003; 15(1): 34-43.

[31] Beeri MS, Werner P, Adar Z, et al. Economic cost of Alzheimer disease in Israel. Alzheimer Dis Assoc Disord 2002; 16(2): 73-80.

[32] Zencir M, Kuzu N, Beser NG, et al. Cost of Alzheimer's disease in a developing country setting. Int J Geriatr Psychiatry 2005; 20(7): 616-22.

[33] Shanmugam A, Monien BH, Bitan G. Development in Diagnostic and Therapeutic Strategies for Alzheimer's Disease. In: Sun M-K Ed., Research Progress in Alzheimer's Disease and Dementia. Nova Science Publishers, Inc., In press.

[34] Doig AJ, Stott K, Treherne JM. Inhibitors of amyloid aggregation: technologies for the discovery of novel lead compounds. Biotech Genet Eng Rev 2004; 21: 197-212.
[35] Wang Z, Chang L, Klein WL, et al. Per-6-substituted-per-6-deoxy $\beta$-cyclodextrins inhibit the formation of $\beta$-amyloid peptide derived soluble oligomers. J Med Chem 2004; 47(13): 3329-33.

[36] Yang F, Lim GP, Begum AN, et al. Curcumin inhibits formation of amyloid $\beta$ oligomers and fibrils, binds plaques, and reduces amyloid in vivo. J Biol Chem 2005; 280(7): 5892-901.

[37] Walsh DM, Townsend M, Podlisny MB, et al. Certain inhibitors of synthetic amyloid $\beta$-peptide $(\mathrm{A} \beta)$ fibrillogenesis block oligomerization of natural $A \beta$ and thereby rescue long-term potentiation. $J$ Neurosci 2005; 25(10): 2455-62.

[38] Necula M, Kayed R, Milton S, et al. Small molecule inhibitors of aggregation indicate that amyloid $\beta$ oligomerization and fibrillization pathways are independent and distinct. J Biol Chem 2007; 282(14): 10311-24.

[39] Kirkitadze MD, Bitan G, Teplow DB. Paradigm shifts in Alzheimer's disease and other neurodegenerative disorders: The emerging role of oligomeric assemblies. J Neurosci Res 2002; 69(5): 567-77.

[40] Klein WL, Stine WB Jr, Teplow DB. Small assemblies of unmodified amyloid $\beta$-protein are the proximate neurotoxin in Alzheimer's disease. Neurobiol Aging 2004; 25(5): 569-80.

[41] Bieler S, Soto C. $\beta$-sheet breakers for Alzheimer's disease therapy. Curr Drug Targets 2004; 5(6): 553-8.

[42] Soto C. Unfolding the role of protein misfolding in neurodegenerative diseases. Nat Rev Neurosci 2003; 4(1): 49-60.

[43] Hilbich C, Kisters-Woike B, Reed J, et al. Substitutions of hydrophobic amino acids reduce the amyloidogenicity of Alzheimer's disease $\beta A 4$ peptides. J Mol Biol 1992; 228(2): 460-73.

[44] Monien BH, Lomakin A, Li H, et al. Mechanistic Insight into the Inhibition of $A \beta 42$ Neurotoxicity by $A \beta 42$ C-terminal Fragments. Manuscript in preparation. 